of treatment was suggested and adopted, but without benefit. I met Mrr. Eccles, and considered my plan of treatment offered a prospect of cure. Mercurial frictions, diuretics, and bandaging, were applied: in ten days ptyalism was produced, and the size of the abdomen reduced from thirty-four and a half to thirty-two inches. Tapping was now performed, and nine pinte and a half of fluid drawn off: the abdomen was again tightly bandaged, and the diuretic medicines continued. Mr. Eccles remarks:- "The case, at this time, (three months from the commencement of the treatment, seems to be perfectly cured. The lady pronounces herself to be in better health than she has been in for years; she is consequently in high spirits, can walk about with ease, and is daily gaining flesh. I have said the case seems to be perfectly cured; but I am not insensible that these are early days to arrive at such a conclusion. What $I$ mean is, that at present there is not the slightest appearance of the re-accumulation of fluid."

About six mont bs subsequently to this a morbid effusion again took place, and the patient consulted an operating physician. The median section was performed; no adhesions existed, and the sac was extracted, but in five days after the operation, the ipatient died.

Before proceeding to offer any rentarks on the thove case, I would subjoin a few important particulars in the history, not mentioned by Mr. Eccles.

The patient stated, that in March, 1844, she was confined, but the clild was weakly, and died in a few hours, which caused her much grief. This brought on, according to her account, great pain in the bowels, which after a time was relieved. In the September following she miscarried while on a visit in the country, where she did not obtain proper medical attendance, and for about three months afterwards suffered from an uterine discharge, and became weak and low-spirited. Moreover, after her miscarriage, instead of decreasing in size she became larger, and this enlargement proceeded gradually. The swelling was attended with great tenderness on pressure, .and was particularly observable on the right side.

Under the impression that the swelling might be the result of her weak state, she paid no attention to it, and did not seek advice till May, 1845. The catamenia remained regular, but were in smaller quantity. Latterly, she suffered from irritation and flatulency of the stomach.

In Dec. 1845, I met Mr. Eccles, and expressed my belief that it was a case of simple ovarian dropsy, discovering no hardened tumour, but only a thin-walled cyst. IIer health was.then much improved, and the usual treatment was com. imenced with. On the 4 th of January, I tapped the crst, as moticed above, and drew off nine pints and a half of fluid, slightly cloudy, like common lemonade, which, on the application of heat, became more cloudy from the precipitation of albumen.

The case advanced favourably, but on the 11 th, she told me she was passing clots of blood per vaginam, which, on examination, $I$ discovered to be the consequence of miscarriage, as I detected portions of the placenta and ovum-a circum. stance, the probability of the occurrence of which she had not led us in the least degree to anticipate. This untoward circumstance rendered it necessary to omit the bandages for a time, until the uterine excitement had passed off.

From the effects of miscarriage she soon recovered, and at the end of three months, as reported by Mr. Eccles, was in the possession of good health, and presented no trace of the ovarian disease.

As before mentioned, however, fluid re-appeared, and the patient decided on having the diseased growth extirpated by the median section. This was done, and she died five days after. No adhesions of the cyst were discoverable.

The fact last mentioned affords me an opportunity of contradicting the statement that has been made-viz., that after the carrying out of my treatment, the opportunity of operating for the removal of the cyst is lost, by reason of the setting up of adhesions.

The treatment of this case was interfered with by the necessary removal of the bandage, on account of the occurrence of miscarriage, as noted in the history; and to this circumstance may, in a great measure, be attributed the want of success, for anything interfering with the constant and due exercise of pressure tends to annul its good effects.

Oxford-square, April, 1849.

Benericence. - The late Sir Thomas Cotton Sheppard, Bart., has left legacies to the following institutions:-The iStaffordshire General Infirmary, £100; the North Staffordshire Infirmary, £100; and the County Lunatic Asylum, $£ 100$.
DESULTORY OBSERVATIONS ON DISEASE AND MEDICAL PRACTICE IN NEW SOUTH WALES.

\author{
Bx F.J. BEARDMORE, Esq., Surgeon, Sydney.
}

INTERNAL aneurisms are exceedingly common in this country; many of the sudden deaths which occur are from this cause,the sac bursting into an internal cavity. I do not remark that they are more common in the lower than in the upper classes; in males than in females. One reason for this occurrence in the labouring class is this:-Men of fine constitution, but dissipated habits, are fond of working by fits and starts, three months of hard work, exerting themselves at times beyond their strength; three months' play, which means drunkenness, \&c. Some years since, a man presented himself at Goulburn Hospital, complaining of pain in the loins and both thighs. Ife was a tall, smart, spare man, about fifty years of age, and a sawyer by trade; he had been ill nine months, owing, he believed, to catching a severe cold. His sufferings at times were excruciating, with intervals of ease, and as he attributed the beginning of his sickness to a severe wetting, he was treated for rheumatism. About ten davs after his admission. I was called one night to see hin: he was dying. Some patients near him remarked that his pains were not those of rheuma tism. I remarked to the wardsman that there was but one thing that it could be, if not rheumatism-viz., the pressure of an aneurism on the spinal cord, and so it proved; an aneurism of the abdominal aorta just below the coliac artery. It extended to the right groin, nearly to the left, and had burst into the left pleura; more or less of the last four dorsal and first lumbar vertebræ were absorbed; the whole bodies of the last two dorsal vertebræ had disappeared, and here the sac was pressing on the cord itself, so that the man experienced no inconvenience of any kind until the cord began to be denuded, which was probably nine months before, and when he first began to experience pain.

North Shore, Sydney, 1849.

\section{A CASE OF MAIAAPRAXIS,-DEATH AND INQUEST.}

By J. PEARSON, M.D., Maryport.

I was called upon, on the 19th of March last, to visit Stephen $\mathrm{B}-$, a collier, residing at Allerby, who, I was told, had received a severe compound fracture of the leg. On my arrival at the patient's residence, I found that the accident had occurred two days previously, and that the bones had been set by a bonesetter. As this person was still in attendance, I told the patient that he must decide whether he would trust himself under my care, or would still continue the bonesetter; that I could not attend *ith such a person; at the same time, strongly impressing both on hini and his friends, that the limb was most improperly treated, and that if allowed to remain in its present state, it was almost impossible that he could re cover-at any rate, he would lose his limb. Notwithstanding this, influenced by the village schoolmaster (!), who was then present, he resolved to continue under the bonesetter's care.

A few words on the nature of the case and treatment. There was compound fracture of both bones of the right leg, the upper end of the tibia denuded of everything but periosteum to the extent of an inch. The tendons of the tibialisanticus and extensor-longus were cut through, and the bellies of the muscles rolled into a heap, the wound in the integuments being very irregular, and, as near as I can recollect, six inches long and four broad. When called to the man, I found the limb laid in a kind of trough, made by joining two pieces of wood together at an angle. This splint, if I may call it so, extended from a little below the knee to the heel; over this and the leg was a kind of bandage, turned here and there as chance happened to place it, and over all was a white breadpoultice, placed upon the bare bone. I could compare the appearance of the muscles \&c. to nothing but half-broiled beef. With such a splint, there was nothing to keep the bones in apposition, and when $I$ saw them, the upper end of the tibia was riding over the lower. No attempt had been made to bring the edges of the wound together; and to crown all, a poultice was placed in the open wound, the village wisdom telling me, that it was "beginning to matter nicely"-nay, I was told, after the inquest, that saltpetre had been applied to the wound. The bonesetter saw him, I believe, three or four times during a period of ten days. Need I say that the case was fatal?

I heard nothing more of the case until told that another practitioner had been called in, the night before his death, eight days from the time I saw him; he was then labouring under tetanus, which had supervened four days previously. 
At the inquest, of which the schoolnaster (of whom the bonesetter was a quondam pupil) was foreman, he, (the schoolmaster, presuming, I suppose, upon his superior wisdom, or perhaps to show his learning to his employers, took upon himself the office of bully, until stopped by the coroner.

In my evidence, I stated that the man had been most grossly maltreated, and that if properly treated his life might have been saved. The coroner, also, in addressing the jury, commented in strong terms upon the neglect the poor man had experienced in being left from the time I saw him to the night of his death without medical assistance, telling them, that blame must attach to some one; that if a person undertook the treatment of a dangerous case, and neglected or maltreated it, he was guilty of manslaughter. The verdict was accidental death.

There can be no doubt that the fracture was the result of an accident, but as no means were employed to ward off the fatal termination, there is every reason to believe that the man's death was the result of neglect and improper treatment.

Maryport, March, 18*9.

\section{CASE OḦ}

\section{LIGATURE OF EXTERNAL ILIAC ARTERY.} BY T. W. NUNN, Esq., M.R.C.S., SURGEON TO THF WESTERN DISPRNSARY, WESTMINSTER, ETC.

JoHN M-, aged forty-three, mason, applied at the Dispensary with a painful swelling in the upper part of the right thigh. The existence of the tumour had been observed by the patient some months previously; but since it had produced only slight occasional inconvenience, no remedy was sought for it.

On examination, the tumour proved to be an aneurism of the common femoral artery, about the size of half a large orange, pulsating with great force, and not capable of being emptied by pressure; it extended a short distance upwards under Poupart's ligament, but its circumference was not very clearly discernible.

The case was seen by my friends, Messrs. Fergusson, De Morgan, Partridge, and Shaw, all of whom agreed on the propriety of immediately placing a ligature upon the external iliac artery.

Accordingly, at two P.M., Jan. 26th, with their assistance, I proceeded to perform the operation, employing the incision parallel with Poupart's ligament, having placed the patient under the influence of chloroform. No unusual difficulty presented itself with regard to the condition of the parts with which it was necessary to interfere; nevertheless, on account of the violent and continued struggling of the patient, and spasmodic contraction of the abdominal muscles, the greatest care was required in the division of the different tissues. The ligature was placed as high up as practicable, withont too much disturbance of the peritonæum, and the wound was closed by four points of suture. No artery of such size as would require tying was wounded. The epigastric vessels and vas deferens were seen, but were left uninjured. The following notes will show the progress of the case:-

Jan. 26th.-Ten P.M.: The patient has felt no particular uneasiness, but complains of a cough, with which he was not troubled before the operation; has had no sleep; pulse 86 ; tongue white. To take, tincture of hyoscyamus, half a drachm, camphor mixture, half an ounce.

27 th.-Cough better; but little sleep; pulse quiet; tongue white; urine abundant and clear; no pain, except when the belly is shaken by the cough. To continue the hyoscyamus. Milk and arrowroot.

28th.-Bowels have been moved for the first time; more sleep; tongue white; pulse 86. To continue hyoscyamus, and take some beef-tea.

29th.-The wound dressed to-day; union taking place throughout the entire length of the wound. Pulse natural, no pain.

30th.-Complains of having suffered pain in the left shoulder during the night; pulse rather feeble. To take a little brandy with the beef-tea.

31st.-Suture producing slight irritation; otherwise perfectly comfortable.

Feb. 1st.- Sutures removed; cough considerably abated.

6 th.-Cough nearly gone. To take some mutton, and continue the brandy, \&c.

8th.-Bowels relaxed; wound looking well. To take fourteen grains of compound chalk powder every four hours. To omit the arrow-root.

10th,-Relaxation continues. To take chalk mixture, with tincture of catechu; if required, ten grains of Dover's powder at bed-time.

11th.-Better. To continue the medicine.

13th.-Better. Wine to be taken instead of brandy.

20th.-Progressing as favourably as possible.

26th, (being the thirty-second day after the operation.)Ligature came away.

March 1st.-Wound entirely closed. The patient is able to move about without inconvenience.

23rd.- No pain has been felt in the tumour, which is now very slowly decreasing in size. The patient considers himself well, and able to resume his usual employment.

Remarks.-The progress of this case was as satisfactory as one could wish. From first to last the patient never complained of an hour's headach, whilst the inconveniences inseparable from a wound of some inches in length through the abdominal parietes were as slight as it is possible to imagine. they would be.

The temperature of the limb was well maintained throughout. On the evening after the operation, the thermometer indicated in the ham of the ligatured side a heat of $95^{\circ}$; while in the hani of the sound sice, and in the axilla, a temperature of $92^{\circ}$ only was attained. Indecd, many days after the operation, the right limb appeared to the hand to be the warmer of the two, though the thermometer did not verify the impression. I consider the chloroform to have been the cause of the troublesome cough mentioned, but fortunately produced no serious harm.

The prognosis in cases of ligature of the external iliac artery is favourable. The above is only one of the many successful operations upon this artery, which, when considered apart from its proximity to the peritonæum, presents, of all other arteries in the body, the most perfect conditions for the successfiul performance of the operation of ligature. The great length of trunk, free from any branches,-for though such are described for the supply of the psoas muscle and lymphatic glands, yet $I$ believe they very rarely exist,-and the distance of the point of ligature from the centre of circulation, are circumstances which, taken together, must mainly contribute towards the happy termination of the majority of the cases in which this proceeding has to be put into exeon tion.

Stratford-place, 1849.

\section{THEORY ON THE \\ SENSE OF TOUCH AND ITS RELATION TO THE VITALITY OF THE BLOOD.}

(AN ABSTRACT.)

By H. L. STUART, Esq., M.R.C.S.E., \&c., Douglas, Isle of Man.

Вотн the posterior and anterior nervous fasciculi, I conceive, are nerves of sensation, or endowed with perceptive sensibility. Yet the posterior nerves may be distinguished as motor nerves, and the anterior as excito-motor nerves.

The muscles, through the medium of the motor nerves; are endowed with negative magnetism, transmitted from the brain and their sensibility is lethal, or unconscious, implying a passive condition, in which the motor principle of life accumulates by repose, constituting a fund of latent heat--a condition which may be expressed by the term letho-negative, and is, in fact, carbon.

By the command of the will, and through the channel of the anterior or excito-motor nerves, a vito-positive spark is transmitted to the muscles, by which their contractile action is excited, motion produced, and latent heat or carbon is evolved from the muscle by the process of condensation, and transferred to the venous blood.

The sense of touch I conceive to be divided between the two sets of nerves; that the motor nerves are perceptive of cold, and the excito-motor nerves are perceptive of heat. Hence the sources of our corporeal sensations of either ex. treme, above or below our standard of heai. But this perception of caloric constitutes only a special sense of touch. Pain constitutes another, resulting from the compression or division of parts, if it does not result from the same principle.

The general sense of touch includes the perceptions of density, form, magnitude, and distance, and constitute the faculty of tact, or the mental perception of muscular motions, which duly guided by the will, and strengthened by experience, lead to the perfection of intuitive manipulation; and those perceptions being the result of muscular motion, are also traceable to the divided influence of the two sets of nerves, as muscular motion depends on their comlined actions. 